\title{
Integrating Project Management, Product Design with Industry Sponsored Projects provides Stimu- lating Senior Capstone Experiences
}

\author{
doi:10.3991/ijep.v1i2.1682
}

\author{
Phillip A. Sanger \\ Western Carolina University, Cullowhee, North Carolina, USA
}

\begin{abstract}
Many students are uncomfortable with real world engineering problems where needs and requirements must be concretely defined and the selection of design solutions is not black and white. This paper describes a two semester, multi-disciplinary senior capstone project for students from three Engineering and Technology Department programs (electrical engineering, electrical and computer engineering technology, and engineering technology) that brings together the tools of project management and the creative product development process into industry sponsored projects. The projects are fully integrated with the Center for Rapid Product Realization with its dual goals of economic development and enhanced learning. The stage/gate development process is used with six formal reviews covering the development of the proposal through to the fabrication and testing of the project's output. Over the past four years thirty five (35) projects have been undertaken with students getting an exciting authentic life experience and introducing them to the real world of engineering.
\end{abstract}

Index Terms — capstone projects, industry, product design, project management

\section{BACKGROUND}

Western Carolina University (WCU), a regional comprehensive institution founded in 1889 with a distinguished history of teaching and learning for western North Carolina has begun the process of alignment with a new focus on innovation. WCU has launched an initiative to engage the resources of the university, its faculty, students, and facilities in the economic growth of the region. At a regional summit held at Cullowhee, NC in February 2003, the university was asked to explore engagement in nontraditional and creative ways ${ }^{1}$. Since that time, numerous initiatives have been launched to stimulate this engagement in new product development, in broadband communications, in adaptive devices, and in rapid prototyping. The conditions are primed for innovative initiatives to convert this enthusiasm into reality. The Kimmel School of Engineering and Construction Management at Western Carolina University plays a leading role in this engagement initiative. The Center for Rapid Product Realization was created to form a bridge and connect the resources of the Kimmel School to the external community. Furthermore the curricular sequence which combines project management, new product development and the student senior capstone project is in full alignment with these recommendations and forms part of the transformation of rural western North Carolina into this new economic mod- el. Our purpose is to produce engineering graduates who are open to the injection of new ideas, comfortable in an environment that will nurture new product ideas from diverse disciplines and can mature promising ideas into actual business propositions.

\section{REGIONAL CONTEXT}

The western North Carolina region is made up of the 23 western-most counties of North Carolina (shown in red in figure 1). This region is larger than eight U.S. states and is approximately the size of Maryland. The demographics of the region are largely rural with a rural population of almost $60 \%$ as compared to the entire state ratio of $39.8 \%$. North Carolina ranks the highest in rural population among the twenty most populous U.S. states. Western North Carolina has a rich history in manufacturing primarily furniture, textiles, and paper. Over the past 20 years, however, and, specifically in the earlier 2001-02 economic slowdown, these industries have been decimated, losing jobs to off-shore-competition and changing market conditions. Sixty nine percent $(69 \%)$ of textile industry layoffs in 2001-02 occurred in rural North Carolina communities ${ }^{2}$. In the great recession of 2008 , employment erosion continues to occur. The manufacturing base of the region is predominantly small businesses and manufact uring units. With that situation comes the long list of

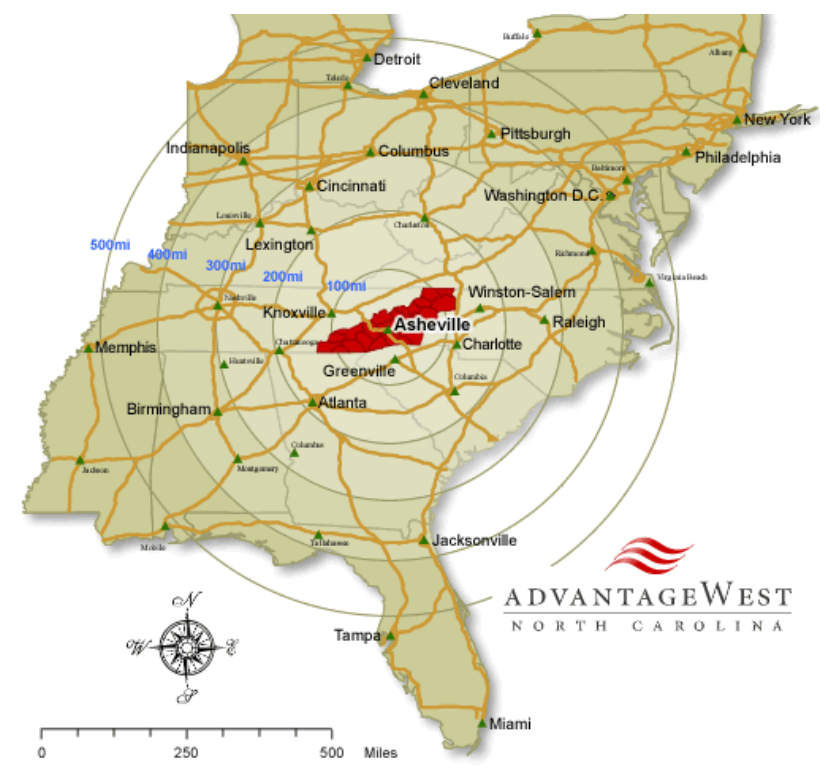

Figure 1. Western Carolina University is in the southern most extension of rural Appalachia. 
challenges that face rural regions including lagging infrastructure, isolation by distance, and weak economic competitiveness. The North Carolina Board of Science and Technology, in its "Tracking Innovation: The North Carolina Innovation Index" reports for 2000 and 2003, recognized that North Carolina needs to strengthen the training of its citizens, particularly its new graduates, for the knowledge-based economy and needs to enhance intellectual property and technology transfer in the marketplace ${ }^{3,4}$. The need for innovative and adaptable engineers is more pronounced in today's struggling economy.

\section{THE CENTER FOR RAPID PRODUCT REALIZATION}

The mission for the Center for Rapid Product Realization (Center) is to match the Kimmel School's expertise and resources to Western North Carolina's needs by forming effective partnerships to grow the region's economy, by assisting in generating value creating jobs and by improving the quality of life for its people. The Center is known and respected throughout the region as an innovative, can-do partner and as the primary resource for technical assistance and technology transfer for government, business and industry officials with local economic growth and job creation responsibilities. The formation and facilitation of multi-disciplinary partnerships will be a hallmark of the Center. The Center will concentrate on two primary goals: economic development and engaged learning.

The programs of the Center for Rapid Product Realization closely support the goals of economic development and engaged learning and are tightly aligned with the strengths of the Department of Engineering and Technology. The central theme that links the technical expertise with the four technical thrust areas is the ability to rapid convert ideas, concepts and processes into productive reality for Western North Carolina. Currently, these areas include opto-electronics, adaptive technologies, concept to manufacturing (including rapid prototyping and reverse engineering), intelligent sensor systems and most recently gas turbine technology. The technical thrusts are coupled and fully integrated with the instructional programs of the Department. Many of these areas have a multi-disciplinary character and this is particularly evident for adaptive technology where the collaboration with special education and physical therapy has been very beneficial.

\section{PedagogicAl ApProACH}

It is clear that creativity, team work, leadership, problem solving, inter-disciplinary integration, and project management have become essential skills if these engineering and technology students are to remain in highdemand and be globally competitive1. These critical skills and particularly project management skills are essential for the Western Carolina University Engineering and Technology program which has adopted the project based learning (PBL) approach. PBL consists of complex tasks and challenging questions or problems that stimulate the students' problem solving, decision making, investigative skills, and reflection. PBL provides a learning environment for the students and promotes learning through investigation and research. Research suggests that the PBL learning experience tends to have a stronger long term positive influence on the students. Accordingly, real-world research questions and problems are great candidates for PBL projects. The students have to think originally and creatively to come up with the solutions to these realworld open-ended questions and problems driving students to encounter the central concepts and principles of the subject hands-on.

For all the Department of Engineering and Technology programs, a full two-semester two course senior capstone project sequence in the B.S. degree has been established and geared toward new product development. This course is also multi-disciplinary where all three curricula, engineering technology, electrical and computer engineering technology and electrical engineering, are combined into one class. All projects must address new problems so that it will draw the students out of their comfort zone consistent with the department's goal of producing graduates capable of self directed learning.

The capstone project in the ET program is a team activity with the team size varying from 2-4 students. The authors have found that more than four students on a team is difficult to manage and to keep all members contributing to the effort. Several techniques have been used for the creation of the teams including self selection, assignment by common project interest and assignment by mixing high and low GPA. Problems and successes have been observed in all the approaches and at this time no technique has been demonstrated to be superior. The most unpopular approach with the students, but the one that has the highest fidelity with the real world, has been the assignment of teams by the instructor. The "best" results in our program have been a balance of instructor assignment and self selection through common interest in a specific project. Students select and prioritize the project topics that they prefer and the instructor then matches and forms teams based on that selection. The authors use the "Teammaker" interview survey provided in the Comprehensive Assessment of Team Member Effectiveness tool (CATME) to assist in forming team based on project preference $^{6}$. This survey gathers information on the individuals themselves and their constraints on team participation. The survey information which can be customized for the particular class includes gender, race, GPA, class year, major, off campus/on campus housing, skills, preferred team role, schedule, commute, and outside employment. It is up to the instructor to create a selection algorithm utilizing these factors.

\section{ApPlying Stage-Gate Structure to ENGINEERING CAPSTONE PROJECTS}

The well known Stage/Gate product development process is applied to all the projects ${ }^{5}$. Project management tools such as work breakdown structures (WBS), Gantt charting, scheduling and quantitative analysis of alternatives (AOA) are introduced and applied by the students in the first course in the sequence, which also spans the project proposal phase of the senior project. The first and second semester are linked through this unified series of stages and gates. Each gate has a set of deliverables and criteria for measuring success. The six gate structure is shown illustratively in Figure 2. The six gates are respectively:

GATE 1 Proposal;

GATE 2 Conceptual Design Review;

GATE 3 Preliminary Design Review;

GATE 4 Critical Design Review; 


\section{GATE 5 Release to Test; and}

\section{GATE 6 Final Project Review.}

The typical timeline for the two course sequence is shown in figure 2 . While the stages and gates are depicted in clean, distinct steps, this depiction hides the normal iterative process that most design projects experience particularly given the built-in open-ended nature of these projects. The deliverables for each of the six gates are shown in Figure 3.

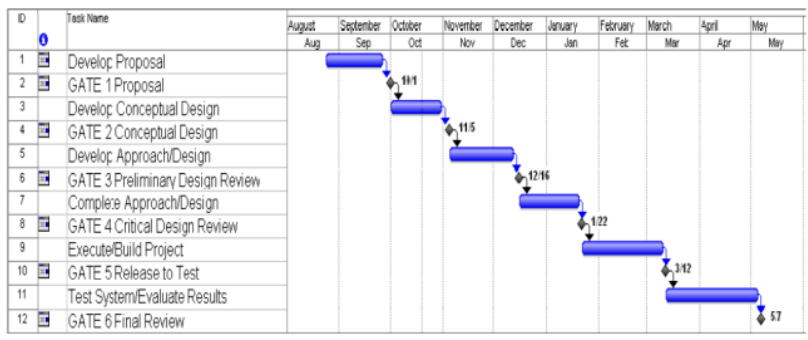

Figure 2. Typical timeline for senior capstone design projects

\begin{tabular}{|l|l|}
\hline \multicolumn{2}{|c|}{ Deliverables for Capstone Project Gates } \\
\hline \multicolumn{1}{|c|}{ First Semester } & \multicolumn{1}{|c|}{ Second Semester } \\
\hline Gate 1 Proposal & Gate 4 Critical Design Review \\
Problem Statement/Context for Project & Design Documentation Package \\
Product Requirements & BOM and Procurement completed \\
\hline Team Charter and Capabilities & Failure Modes and Effects Analysis Completed \\
WBS and Schedule for Conceptual Design Phase & WBS and Schedule for Project Completion \\
10 min Presentation plus Project Report & I hour Detailed Review plus Project Report \\
\hline Gate 2 Conceptual Design & Gate 5 Release to Test \\
Refinement of Requirements & Updated Schedule \\
Three Conceptual Designs & Prototype Completed, \\
WBS and Schedule for Design Phase & As built Documentation \\
Budget & Test Plan finalized \\
\hline I hour Detailed Review plus Project Report & Show Me Review plus Project Report \\
\hline Gate 3 Preliminary Design Review & Gate 6 Project Completion \\
Design Progress & Testing Report \\
Long Lead Items & Design Documentation Package \\
Updated Schedule & Modifications completed \\
Poster Session plus Project Report & Final Project Presentations to External Reviewers \\
\hline
\end{tabular}

Figure 3. Written and oral deliverables are required at each gate.

At the beginning of the first semester of this two course sequence, all the students are provided a catalog of projects proposed by the local industry partners. Potential projects have been solicited from industry and carefully triaged. To be suitable for senior capstone projects, the projects must:

- Be open ended requiring evaluation of multiple solutions

- Be complex and challenging requiring innovation, out of the box thinking,

- Be on subjects just beyond their present courses, requiring self directed learning

- Have sufficient scope that would require a team approach

Only those projects that meet these requirements are included in the catalog. The most common topics for projects have tended to be projects involving the development of new products or new processes since they fit very well with the Stage/Gate formulism. However basic research can also fit this formulism if it is realized that the new product from basic research is new knowledge $\mathrm{e}^{7}$. The stages can remain the same while the activities change. For example, in basic research, the fabrication stage is the act of generating the data or running the experiment and not building of hardware and the testing phase becomes evalu- ating the data and assessing its validity against models and theory.

Students are asked to select their five top project choices from which teams are formed. In the 2010-2011 class, 24 projects were offered and 15 projects were taken on by student teams. In addition to the student members, each team is provided a faculty mentor as well as an industry mentor to guide the activities.

Gate 1 Proposal Review: The focus of Gate 1 is to ensure that the team understands the problem that they are addressing. As a result the most critical deliverable for Gate 1 is the requirements matrix. The teams are encouraged to visit their customers and initiate regular communication schedules for the project. At Gate 1, the teams will formulate and propose the first WBS/Schedule for the project. In order to facilitate the learning process, the teams are only asked to breakdown and schedule the conceptual design stage. Concurrent tasks are encouraged. Important dimensions of the conceptual phase are 1) researching of existing products and solutions and 2) investigative experimentation. Trials with conceptual ideas and handmade artifacts are important tools for concept development.

Gate 2: Conceptual Design Review: It has been our experience that students typically gravitate to the first solutions that seems to fit. Later in the development the students are unwilling or unable to let the approach go despite the discovery of major flaws. To avoid this situation, the teams are required at Gate 2 to present three (3) designs that meet all the design requirements. Subsequently in the design phase they will be required to downselect using formal analysis of alternative (AOA) tools.

The review process in the series of gates has been selected to both meet the needs of the projects and give the students experience in a variety of review formats. At Gate 2 , the review format is an hour long, detailed interactive review of the project. This style will be repeated at Gate 4 as well by request of the students who found that this interactive style of review was highly beneficial to the team.

Gate 3 Preliminary Design Review: The detailed design phase includes both Gate 3 and Gate 4 . The role of Gate 3 is primarily to monitor progress and ensure that materials and components that require long delivery times are on order prior to the semester break.

Gate 4 Critical Design Review: This is the most critical of all the reviews. The next stage is fabrication and construction and, if the design is weak or incomplete, the next stage of fabrication will be very difficult. To uncover flaws in the design, the team is required to complete a failure modes and effects analysis (FMEA). This FMEA should have precipitated, during the design process, a critical examination of design aspects to avoid serious design failures. The interactive review process facilitates a thorough exploration of the design.

Gate 5 Release to Test: The fabrication stage is intended to produce a prototype. Along the way, design changes are inevitable. The team is required to maintain an as-built file folder to document the build and manage the configuration of the product. The team is encouraged to incorporate components and subassembly testing into their fabrication process. However one of the deliverables at the end of the fabrication stage is a written test plan to be followed in the final testing phase. The testing plan includes in process testing, internal laboratory testing and final field testing. If 

CAPSTONE EXPERIENCES

the testing includes the use of human subjects, the testing plan must be review and approved by the WCU internal review board (IRB).

Gate 6 Final Project Review: The final review for the 8 month senior capstone project is the final wrap up of the documentation, test results and often modifications to resolve issues revealed through the testing.

\section{ASSESSMENT AND GRADING}

The grading system for the two semesters has three components: gate score including a peer to peer assessment, their personal logbook, and their class participation.

Each review, three in each semester, is awarded $25 \%$ of the grade. This $25 \%$ is based on rubrics filled out by mentors and faculty, on Gate project reports and on a peer to peer assessment of contribution using the web based CATME assessment tools ${ }^{6}$. The student has access to his/her CATME evaluation immediately after the survey is completed and is able to make adjustments as indicated by the survey. In addition the CATME tool provides the faculty member insight into problems that are occurring within the teams which allow the faculty member to take corrective action.

Each student is required to maintain a personal project logbook. This logbook simulates the traditional notebooks that engineers are often required to maintain in industry for intellectual property management. Each entry is dated, written in ink and contains class notes, team meeting minutes, action items from meetings, design sketches and other project information. At each gate, the logbook is reviewed and awarded $5 \%$ of the final grade for a total of $15 \%$.

Finally $10 \%$ of the grade is awarded based on class participation and homework. Several individual homework activities were assigned and graded. For example students were asked to create a work breakdown structure, task relationship and schedule for a family celebration or party. A second example was to perform a formal trade study on the purchase of a vehicle. Students have many opportunities to volunteer to show their solutions and team documentation in class.

\section{PROJECT EXAMPLES}

In four years, thirty five (35) projects have been initiated. The number of industry sponsored projects has increased from $16 \%$ to $87 \%$. The senior capstone topics for academic year 2010-2011 included the following titles and their sponsoring companies:

- Seal Face Protection and Packaging System--Caterpillar Precision Seals

- Metal Seal Inspection System ----Caterpillar Precision Seals

- Solar Thermal Controller Communication System --FLS Energy, Inc.

- Improved Solar Box Heat Collector----FLS Energy, Inc.

- Automated "Poking" of Biomedical Mandrels--Curtis Wright (Shelby, NC)

- 737/777 Actuator Test System----Curtis Wright (Shelby, NC)

- Physical world system simulation using a Computing Cluster---Western Carolina University
- System for Putting on Leg Compression Garment--Siskin Hospital Lymphedema Clinic

- Affordable Manually Operated Handicapped Assist Mobility Device---Technovashun Chapel Hill, NC

- Battery Powered Wireless Brachy Lighting System--Shands Medical Center

- Powered torque wrench or Air Ratchet Wrench with Integrated Electronic Torque Wrench----Snap-On, Murphy, NC

- A Compressor Cascade Wind Tunnel---Edmonds Consulting Corporation

- Design and build a Solar Tree for the WCU Campus---Western Carolina University

Here are more details on some of the interesting and challenging project undertaken by student teams in prior year senior projects.

\section{A. Total Knee Replacement Rehabilitation Device}

The project sought to develop a device for home use to assist the patient in achieving full range of motion following a total knee replacement operation (see figure 4). Immediately following the surgery, scar tissue forms around the new knee components. To prevent this scarring from freezing the knee and limiting the range of motion and flexibility, it is necessary to stretch the knee several times a day. No device exists to assist the patient in this exercise and several student teams working with an orthopedic surgeon developed a low cost device to assist the patient. Patent disclosures have been submitted including the students as inventors.

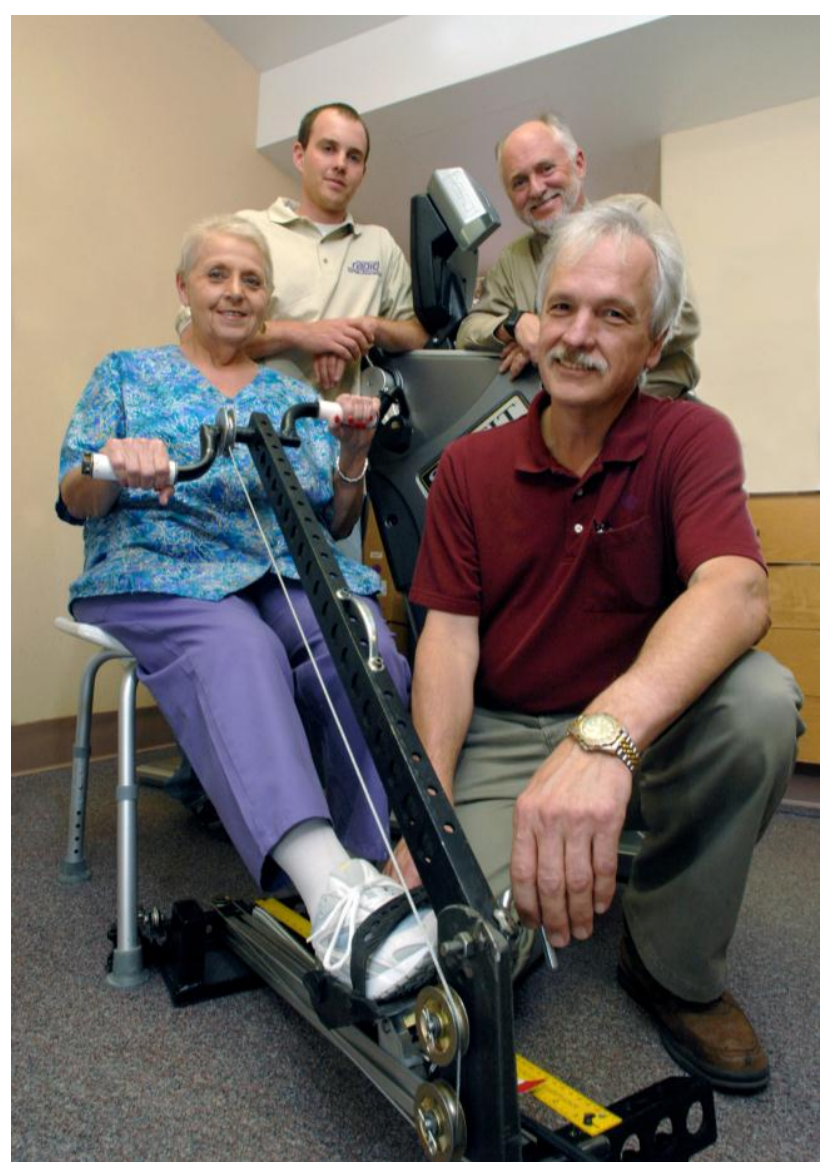

Figure 4. Student and orthopedic surgeon create rehabilitation device for patients recovering from total knee replacement. 
PAPER

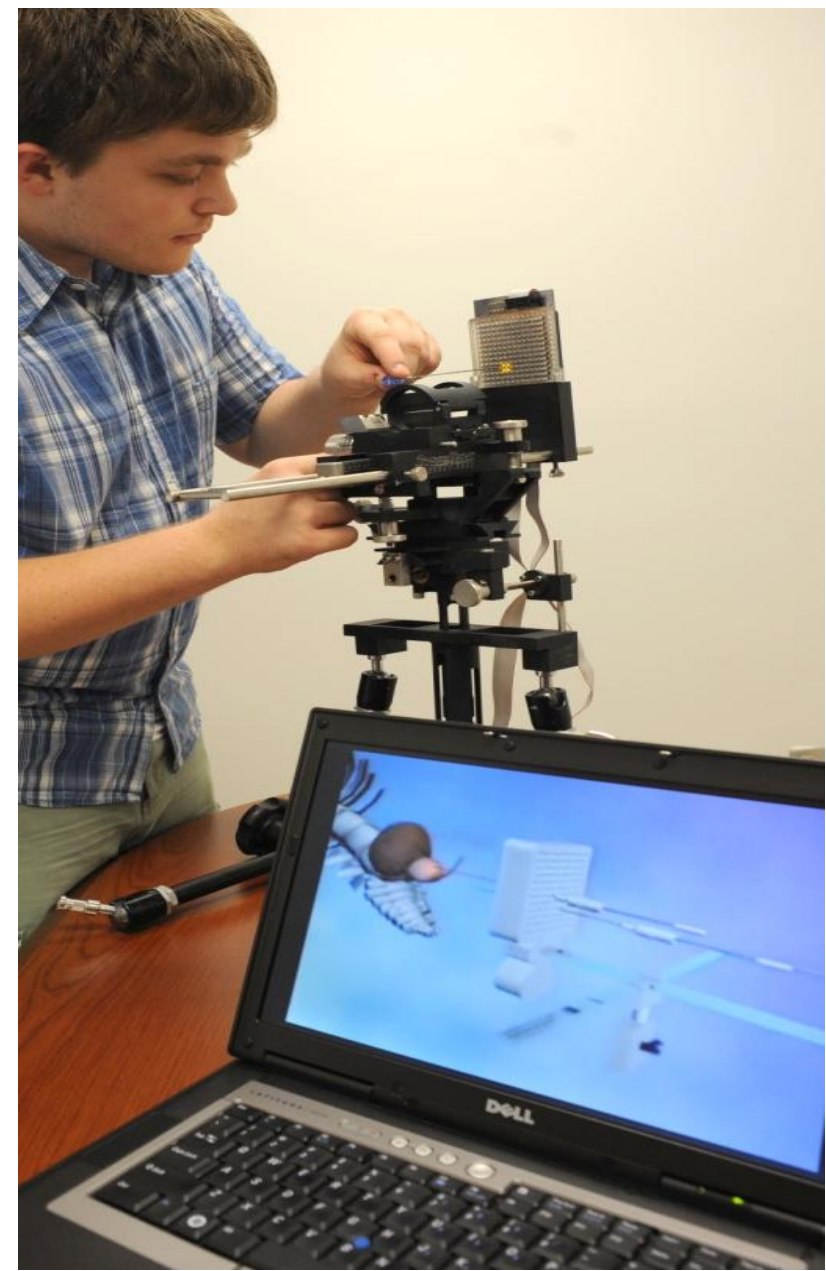

Figure 5. The lighting system aids in accurate placement of radioactive seeds during Brachy therapy.

\section{B. LED Lighting System to Assist Prostate Cancer Treatment}

Brachytherapy treats cancerous prostate tissue by implanting radioactive seeds into the prostate ${ }^{8}$. Brachtherapy is minimally invasive and is very effective. Current method of seed implantation required verbal communication between the medical physicist and the physician during the insertion of the radioactive seeds and is susceptible to error due to verbal miscommunication and poor lighting. A student team started the development of a disposable LED lighting system and developed software to connect physician treatment plan to seed implantation. A second team is improving the design by making the system wireless and battery powered.

\section{Design and Build a Solar Tree for the WCU Campus:}

Western Carolina University in collaboration with Consolidated Edison won a sizable grant focused on injecting renewable energy solutions to the WCU campus. One of the tasks was to build a PV Solar tree as a highly visible symbol of renewable energy on campus. The tree is to produce $3.4 \mathrm{~kW}$ of energy and the photovoltaic "leaves" will follow the diurnal movement of the sun. The student team was asked to design an aestetically pleasing mechanical structure and then prototype one of the leaf sections and validate the articulating system and the mechanical structure.

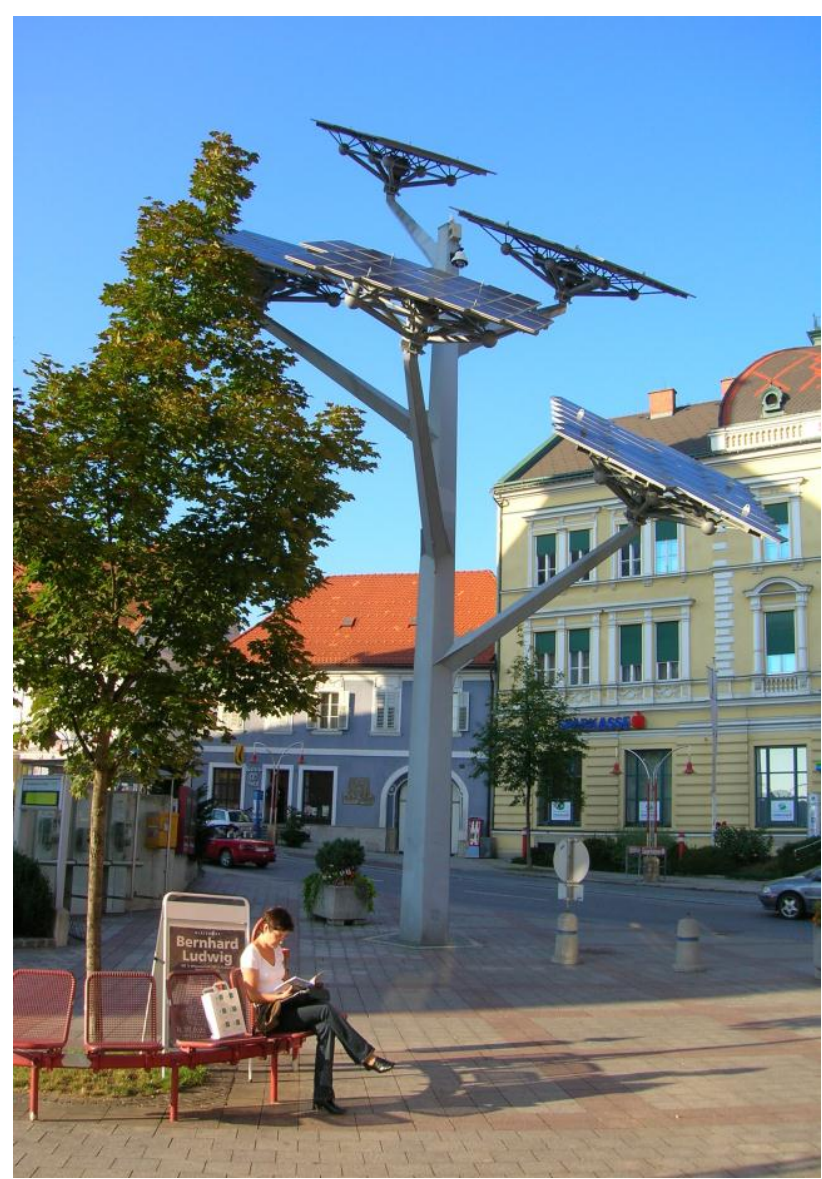

Figure 6. The team is evaluating a design similar to the solar tree in Gleisdorf, Austria ${ }^{9}$

\section{CONCLUSION}

The creation of a two semester interdisciplinary senior capstone course integrated with project management and product design has developed into a successful course structure. The Rapid Center plays a key in soliciting and acquiring enthusiastic industry support with $86 \%$ of the projects receiving sponsorship and industry mentors. This co-mingling of disciplines, electrical, mechanical and computer engineering, has set the stage for more challenging interdisciplinary capstone projects.

\section{ACKNOWLEDGMENT}

This program would not be possible if it were not for the enthusiastic support from many people: the Department of Engineering and Technology faculty, Dr. Ken Burbank, our department head, Dr. Robert McMahan, the dean of the Kimmel School and the many industry sponsors who offer real life experiences to our students through these projects.

\section{REFERENCES}

[1] Western Carolina University, "A regional summit: Meeting Western North Carolina's needs through higher education", http://www.wcu.edu/chancellor/Presentations/regional\%20summit. htm. Retrieved May 18, 2005 (2003)

[2] Making a Difference in Communities in the South. (2002). State of the south 2002: Shadows in the sunbelt revisited. Retrieved May 21, 2005 from http://www.mdcinc.org/pdfs/ sos2002report.pdf

[3] North Carolina Board of Science and Technology, "Tracking Innovation: North Carolina innovation index 2000", 
PAPER

Integrating Project Management, Product Design with Industry Sponsored Projects Provides Stimulating Senior CAPSTONE EXPERIENCES

http://www.ncscienceandtechnology.com/PDF/Vision2030/Tracki ngInnovation2000.pdf, Retrieved May 27, 2005 (2000)

[4] North Carolina Board of Science and Technology, "Tracking Innovation: North Carolina innovation index 2003”, http://www.ncscienceandtechnology.com/PDF/2003/TrackingInno vation2003.pdf, Retrieved May 27, 2005, (2003).

[5] Robert G. Cooper, Winning at New Products- Accelerating the Process from Idea to Launch, Cambridge, MA. Perseus Publishing, 2001.

[6] The Web-based Comprehensive Assessment of Team Member Effectiveness, http://www.CATME.org.

[7] W. Yang, P. A. Sanger, P. Gardner, "Teaching and Learning of Project Management for Engineering and Technology Capstone Research Projects," 2010 ASEE Annual Conference, Louisville, KY, 2010.
[8] For a fully description of the brachytherapy procedure, the reader is referred to the American Brachytherapy Society http://www. americanbrachytherapy.org/aboutBrachytherapy/brachy.cfm.

[9] Anna Regelsberger, created 12. Aug. 2005 http://en.wikipedia.org/ wiki/File:Gleisdorf.Solarbaum.jpg .

\section{AUTHOR}

P. A. Sanger (sanger@wcu.edu) is an Associate Professor in the Engineering and Technology Department as well as the Director of Center for Rapid Product Realization at Western Carolina University, Cullowhee, NC, USA 28723.

Received May $24^{\text {th }}, 2011$. Published as resubmitted by the authors June $16^{\text {th }}, 2011$. 